\title{
PENGENDALIAN MUTU PRODUKSI BERAT SEMEN PT. SEMEN PADANG DENGAN BAGAN KENDALI SHEWHART DAN ROBUST
}

\author{
RELIGEA REZA PUTRI, FERRA YANUAR, DODI DEVIANTO \\ Program Studi Matematika, \\ Fakultas Matematika dan Ilmu Pengetahuan Alam, Universitas Andalas, \\ Kampus UNAND Limau Manis Padang, Indonesia. \\ email : religeareza@gmail.com
}

\begin{abstract}
Abstrak. Bagan kendali Shewhart terdiri dari dua macam bagan kendali yaitu bagan kendali variabel dan bagan kendali atribut. Bagan kendali variabel dibedakan atas tiga bagan kendali yaitu bagan kendali $I-M R, \bar{X}-R, \bar{X}-S$.Bagan kendali Robust adalah bagan kendali yang tahan terhadap data pencilan. Penduga yang digunakan pada bagan kendali Robust adalah penduga Hodges-Lehman dan penduga Shamos-Bickel-Lehman. Pada penelitian kali ini, sebagai aplikasi yang diterapkan untuk membuat bagan kendali proses pengukuran berat semen, menggunakan metode bagan kendali Shewhart (bagan kendali $\bar{X}-R$ ) dan bagan kendali Robust. Proses pengukuran berat semen adalah kemasan 50kg yang diproduksi oleh PT. Semen Padang. Proses yang terjadi menurut kedua bagan kendali adalah out of control.
\end{abstract}

Kata Kunci: Bagan Kendali Shewhart, Bagan Kendali Robust, Bagan Kendali Variabel, Bagan Kendali $\bar{X}-S$, Penduga Hodges-Lehmann, Penduga Shamos-Bickel-Lehmann

\section{Pendahuluan}

Setiap proses produksi selalu menghasilkan produk yang bervariasi, bagaimanapun bagusnya rancangan dan pelaksanaan proses produksi tersebut. Agar variasi mutu tidak menimbulkan masalah pada produk yang dihasilkan, sehingga produk sesuai dengan spesifikasi yang telah ditetapkan, maka dilakukan proses pengandalian mutu. Pengendalian proses di sini adalah pengendalian proses secara statistik (Statistical Process Control disingkat SPC). Pengendalian mutu mulai dikenal sejak awal abad ke-19 ketika Ellias Whitney memperkenalkan perlunya pengendalian mutu dalam perusahaan industri. Pada tahun 1924, Dr. Walter Shewhart memperkenalkan bagan kendali (control chart) dalam pengendalian mutu dan membedakan penyebab terjadinya variasi khusus dan umum. Peta kendali memiliki batas-batas yang menunjukkan proses berjalan memenuhi standar atau belum. Peta kendali yang dikembangkan oleh Walter Shewhart dikenal dengan sebutan bagan kendali Shewhart.

Bagan kendali robust adalah bagan kendali yang tahan terhadap keberadaan outlier, sehingga taksirannya tidak berubah oleh sedikit penyimpangan asumsi distribusinya. Penduga Hodges Lehmann (HL) untuk menduga ukuran terpusat data. Penduga Shamos-Bickel-Lehmann (SBL) untuk mengukur ukuran pencaran data $[1]$. 


\section{Data dan Metode}

Data yang digunakan untuk mengaplikasikan kedua bagan kendali adalah data sekunder berupa data berat semen dalam kemasan berukuran $50 \mathrm{~kg}$ pada bulan Januari 2013-Juli 2015, yang diambil di PT. Semen Padang. PT. Semen Padang merupakan pabrik semen tertua di Indonesia yang didirikan pada 18 Maret 1910 dengan nama NV NIPCM (Netherlandsch Indieche Portland Cement Maatschaapi). Data yang didapat adalah untuk 31 subgrup, masing-masing subgrup terdiri dari lima sampel. Toleransi berat semen yang ditetapkan oleh pihak manajemen dalam pengantongan semen dengan menggunakan kantong jahit adalah 50,50 $\pm 0,25 \mathrm{~kg}$.

Untuk pembuatan bagan kendali $\bar{X}$ dan $R$ dilakukan langkah-langkah berikut :

(1) Hitung $\bar{X}$ dan $R$ untuk masing-masing subgrup.

dimana $\bar{X}=\frac{\sum_{i}^{n} x_{i}}{n}$ dan $R=R_{\max }-R_{\min }$

(2) Hitung rata-rata $\bar{X}(\overline{\bar{X}})$ dan rata-rata range $(\bar{R})$ dari keseluruhan subgrup, dengan $\overline{\bar{X}}=\frac{\sum_{i=1}^{m} \bar{X}_{i}}{m}$ dan $R=\frac{\sum_{i=1}^{m} R_{i}}{m}$

(3) Hitung UCL, CL dan LCL untuk bagan kendali $\bar{X}$ yaitu:

$$
\begin{aligned}
U C L_{X} & =\overline{\bar{X}}+3 \frac{\bar{R}}{d_{2} \sqrt{n}} \\
C L_{\bar{X}} & =\overline{\bar{X}} \\
L C L_{\bar{X}} & =\overline{\bar{X}}-3 \frac{\bar{R}}{d_{2 \sqrt{n}}} .
\end{aligned}
$$

$n$ adalah ukuran sampel yang diambil dalam tiap subgrup, nilai $d_{2}$ dilihat di tabel. Sedangkan untuk bagan kendali $R$ adalah :

$$
\begin{aligned}
U C L_{R} & =\overline{\bar{R}}+3 d_{3} \frac{\bar{R}}{d_{2}} \\
C L_{R} & =\bar{R} \\
L C L_{R} & =\bar{R}-3 d_{3} \frac{\bar{R}}{d_{2}}
\end{aligned}
$$

nilai $d_{2}$ dan $d_{3}$ diperoleh dari tabel.

(4) Bentuk bagan kendali dengan membuat plot nilai $\bar{X}$ dan $R$ untuk setiap subgrup pada garis vertikal berdasarkan urutan nomor subgrup pada garis horizontalnya.

(5) Lakukan analisis terhadap kedua bagan kendali dengan menentukan proses terkendali atau tidak.

Untuk pembuatan bagan kendali Robust dilakukan langkah-langkah berikut :

(1) Hitung $M$ dan rata-rata walsh $\left(W_{r}\right)$ menggunakan persamaan berikut.

$$
\begin{aligned}
M & =\frac{n(n+1)}{2}, \\
W_{r} & =\frac{X_{i}+X_{j}}{2}, i \leq j, i, j=1,2, \cdots, n, r=1,2, \cdots, m .
\end{aligned}
$$


(2) Urutkan $W_{(i, 1)} \leq W_{(i, 2)} \leq \cdots \leq W_{(i, M)}$ dimana $W_{(i, k)}$ menyatakan rata-rata Walsh urutan ke- $k$ dari subgrup ke- $i$

(3) Hitung penduga HL dengan menggunakan persamaan berikut

$$
H L=\left\{\begin{array}{ll}
W_{(k+1)}, & \text { untuk } M \text { ganjil } \\
\left(W_{(k)}+W_{(k+1)}\right) / 2, & \text { untuk } M \text { genap }
\end{array},\right.
$$

dimana

$$
k=\left\{\begin{array}{ll}
(M-1) / 2, & \text { untuk } M \text { ganjil } \\
M / 2, & \text { untuk } M \text { genap }
\end{array} .\right.
$$

(4) Hitung $U$ dan $B_{i, j, l}$, dengan persamaan berikut.

$$
\begin{aligned}
U & =\left(\begin{array}{l}
n \\
2
\end{array}\right)=\frac{n !}{2 !(n-2) !}, \\
B_{i, j, l} & =\left|x_{i, j}-x_{i, l}\right|, i, j=1,2, \cdots, n, l=1,2, \cdots, m .
\end{aligned}
$$

(5) Buat urutan $B_{(i, 1)} \leq B_{(i, 2)} \leq \cdots \leq B_{(i, U)}$ dimana $B_{i, j, l}$ menyatakan urutan ke- $k$ dalam subgrup ke- $i$.

(6) Hitung penduga SBL dengan menggunakan persamaan berikut

$$
S B L=\left\{\begin{array}{ll}
B_{(k+1)}, & \text { untuk } U \text { ganjil } \\
\left(B_{(k)}+B_{(k+1)}\right) / 2, & \text { untuk } U \text { genap }
\end{array},\right.
$$

dimana

$$
k=\left\{\begin{array}{ll}
(U-1) / 2, & \text { untuk } U \text { ganjil } \\
U / 2, & \text { untuk } U \text { genap }
\end{array} .\right.
$$

(7) Hitung nilai rata-rata penduga HL dan SBL dengan menggunakan persamaan berikut

$$
\bar{H} L=\frac{\sum_{i=1}^{m} \widehat{H L}}{m} \text { dan } S \bar{B} L=\frac{\sum_{i=1}^{m} \widehat{S B L}}{m}
$$

(8) Hitung batas kendali $3 \sigma$ untuk bagan kendali Robust sebagai berikut.

$$
\begin{aligned}
U C L & =\bar{H} L+3 c_{4} S \bar{B} L \\
C L & =\bar{H} L \\
L C L & =\bar{H} L-3 c_{4} S \bar{B} L
\end{aligned}
$$

Nilai untuk faktor $c_{4}$ tergantung dari ukuran subgrup yang didapat dari tabel.

(9) Tentukan nilai-nilai $H L$ untuk keseluruhan subgrup dan plot nilai-nilai tersebut ke dalam bagan kendali.

(10) Lakukan analisis terhadap bagan kendali dengan menentukan proses terkendali atau tidak.

Setelah kedua bagan kendali terbentuk, dilakukan analisis perbandingan antara kedua jenis bagan kendali yang dihasilkan untuk masing-masing jenis data.

\section{Hasil dan Pembahasan}

Pada Tabel 1 diberikan data berat semen yang diperoleh dari PT. Semen Padang. Untuk membandingkan metode bagan kendali yang digunakan maka data berat semen asal akan dimodifikasi sehingga diperoleh ada data asal sebuah data pencilan 
pada subgrup ke-3 dan pada sampel ke-2. Pada Tabel 2 diberikan data berat semen yang telah dimodifikasi.

Tabel 1. Data Berat Semen Asal (Data Berat Semen Normal Tanpa Pencilan)

\begin{tabular}{|c|c|c|c|c|c|c|c|c|c|c|c|}
\hline \multirow{2}{*}{$\begin{array}{c}\text { Numb. } \\
\text { Of Sub } \\
\text { Grup }\end{array}$} & \multicolumn{5}{|c|}{ Sampel Ke } & \multirow{2}{*}{$\begin{array}{c}\text { Numb. } \\
\text { Of Sub } \\
\text { Grup }\end{array}$} & \multicolumn{5}{|c|}{ Sampel Ke } \\
\hline & 1 & 2 & 3 & 4 & 5 & & 1 & 2 & 3 & 4 & 5 \\
\hline 1 & 50.46 & 50.39 & 50.43 & 50.38 & 50.45 & 17 & 50.4 & 50.37 & 50.35 & 50.4 & 50.36 \\
\hline 2 & 50.44 & 50.36 & 50.43 & 50.4 & 50.44 & 18 & 50.41 & 50.4 & 50.4 & 50.4 & 50.4 \\
\hline 3 & 50.45 & 50.42 & 50.44 & 50.46 & 50.48 & 19 & 50.32 & 50.37 & 50.37 & 50.36 & 50.32 \\
\hline 4 & 50.46 & 50.41 & 50.41 & 50.4 & 50.48 & 20 & 50.33 & 50.32 & 50.32 & 50.33 & 50.32 \\
\hline 5 & 50.43 & 50.34 & 50.3 & 50.3 & 50.36 & 21 & 50.34 & 50.33 & 50.33 & 50.31 & 50.34 \\
\hline 6 & 50.42 & 50.41 & 50.37 & 50.33 & 50.4 & 22 & 50.34 & 50.34 & 50.31 & 50.31 & 50.35 \\
\hline 7 & 50.44 & 50.39 & 50.36 & 50.32 & 50.37 & 23 & 50.3 & 50.27 & 50.29 & 50.28 & 50.29 \\
\hline 8 & 50.38 & 50.43 & 50.33 & 50.4 & 50.35 & 24 & 50.3 & 50.26 & 50.31 & 50.33 & 50.26 \\
\hline 9 & 50.34 & 50.38 & 50.35 & 50.35 & 50.3 & 25 & 50.31 & 50.27 & 50.26 & 50.26 & 50.27 \\
\hline 10 & 50.42 & 50.36 & 50.38 & 50.36 & 50.38 & 26 & 50.32 & 50.32 & 50.33 & 50.34 & 50.32 \\
\hline 11 & 50.4 & 50.32 & 50.31 & 50.3 & 50.39 & 27 & 50.3 & 50.33 & 50.31 & 50.29 & 50.29 \\
\hline 12 & 50.31 & 50.23 & 50.23 & 50.23 & 50.3 & 28 & 50.33 & 50.41 & 50.43 & 50.41 & 50.38 \\
\hline 13 & 50.31 & 50.25 & 50.26 & 50.26 & 50.32 & 29 & 50.32 & 50.44 & 50.44 & 50.44 & 50.38 \\
\hline 14 & 50.32 & 50.31 & 50.33 & 50.31 & 50.35 & 30 & 50.32 & 50.47 & 50.46 & 50.42 & 50.38 \\
\hline 15 & 50.35 & 50.31 & 50.3 & 50.31 & 50.31 & 31 & 50.31 & 50.41 & 50.37 & 50.34 & 50.34 \\
\hline 16 & 50.36 & 50.34 & 50.34 & 50.38 & 50.35 & & & & & & \\
\hline
\end{tabular}

Tabel 2. Data Berat Semen Modifikasi (Data Berat Semen Normal Dengan Pencilan)

\begin{tabular}{|c|c|c|c|c|c|c|c|c|c|c|c|}
\hline \multirow{2}{*}{$\begin{array}{c}\text { Numb. } \\
\text { Of Sub } \\
\text { Grup }\end{array}$} & \multicolumn{5}{|c|}{ Sampel Ke } & \multirow{2}{*}{$\begin{array}{c}\text { Numb. } \\
\text { Of Sub } \\
\text { Grup }\end{array}$} & \multicolumn{5}{|c|}{ Sampel Ke } \\
\hline & 1 & 2 & 3 & 4 & 5 & & 1 & 2 & 3 & 4 & 5 \\
\hline 1 & 50.46 & 50.39 & 50.43 & 50.38 & 50.45 & 17 & 50.4 & 50.37 & 50.35 & 50.4 & 50.36 \\
\hline 2 & 50.44 & 50.36 & 50.43 & 50.4 & 50.44 & 18 & 50.41 & 50.4 & 50.4 & 50.4 & 50.4 \\
\hline 3 & 50.45 & 51 & 50.44 & 50.46 & 50.48 & 19 & 50.32 & 50.37 & 50.37 & 50.36 & 50.32 \\
\hline 4 & 50.46 & 50.41 & 50.41 & 50.4 & 50.48 & 20 & 50.33 & 50.32 & 50.32 & 50.33 & 50.32 \\
\hline 5 & 50.43 & 50.34 & 50.3 & 50.3 & 50.36 & 21 & 50.34 & 50.33 & 50.33 & 50.31 & 50.34 \\
\hline 6 & 50.42 & 50.41 & 50.37 & 50.33 & 50.4 & 22 & 50.34 & 50.34 & 50.31 & 50.31 & 50.35 \\
\hline 7 & 50.44 & 50.39 & 50.36 & 50.32 & 50.37 & 23 & 50.3 & 50.27 & 50.29 & 50.28 & 50.29 \\
\hline 8 & 50.38 & 50.43 & 50.33 & 50.4 & 50.35 & 24 & 50.3 & 50.26 & 50.31 & 50.33 & 50.26 \\
\hline 9 & 50.34 & 50.38 & 50.35 & 50.35 & 50.3 & 25 & 50.31 & 50.27 & 50.26 & 50.26 & 50.27 \\
\hline 10 & 50.42 & 50.36 & 50.38 & 50.36 & 50.38 & 26 & 50.32 & 50.32 & 50.33 & 50.34 & 50.32 \\
\hline 11 & 50.4 & 50.32 & 50.31 & 50.3 & 50.39 & 27 & 50.3 & 50.33 & 50.31 & 50.29 & 50.29 \\
\hline 12 & 50.31 & 50.23 & 50.23 & 50.23 & 50.3 & 28 & 50.33 & 50.41 & 50.43 & 50.41 & 50.38 \\
\hline 13 & 50.31 & 50.25 & 50.26 & 50.26 & 50.32 & 29 & 50.32 & 50.44 & 50.44 & 50.44 & 50.38 \\
\hline 14 & 50.32 & 50.31 & 50.33 & 50.31 & 50.35 & 30 & 50.32 & 50.47 & 50.46 & 50.42 & 50.38 \\
\hline 15 & 50.35 & 50.31 & 50.3 & 50.31 & 50.31 & 31 & 50.31 & 50.41 & 50.37 & 50.34 & 50.34 \\
\hline 16 & 50.36 & 50.34 & 50.34 & 50.38 & 50.35 & & & & & & \\
\hline
\end{tabular}

Nilai rata-rata dan range pada setiap subgrupdata berat semen normal tanpa pencilan akan diplotkan kedalam sebuah diagram dengan batas kendali sesuai peraturan pembuatan bagan kendali shewhart. Sehingga akan diperoleh bagan kendali pada Gambar 1.

Dari plot pada Gambar 1 dapat dilihat bahwa pada bagan kendali $\bar{X}$ terdapat tujuh titik berada diatas batas atas kendali yaitu pada subgrup 1,2, 3, 4, 18, 29, 30 . Dan terdapat enam titik yang berada dibawah bagan kendali bawah, yaitu pada subgrup $12,13,23,24,25,27$. Dengan demikian dapat disimpulkan bahwa rata-rata berat semen pada bagan kendali $\bar{X}$ berada diluar batas kendali. 


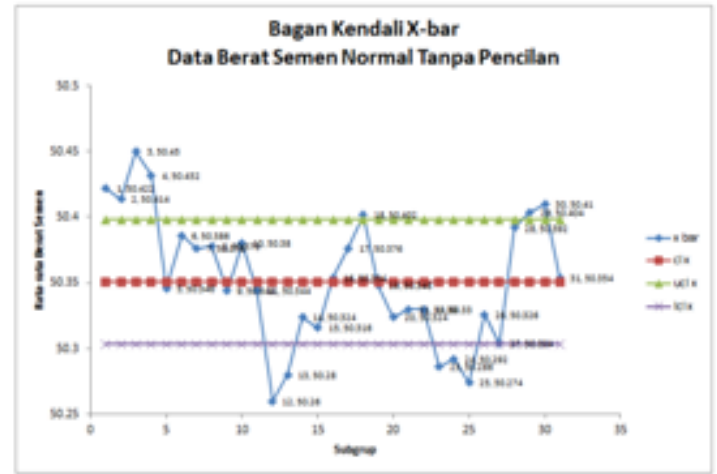

Gambar 1. Bagan kendali $\bar{X}$ data berat semen normal tanpa pencilan

Dengan menghitung nilai rata-rata dan range data berat semen normal dengan pencilan maka dapat dihasilkan bagan kendali pada Gambar 2.

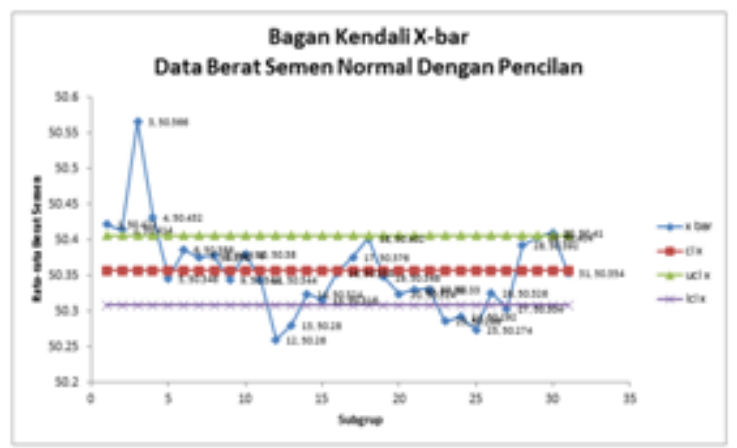

Gambar 2. Bagan kendali $\bar{X}$ dengan data berat semen normal dengan pencilan

Dari plot pada Gambar 2 dapat dilihat bahwa pada bagan kendali $\bar{X}$ terdapat lima titik berada diatas batas atas kendali yaitu pada subgrup 1, 2, 3, 4, 30. Dan terdapat enam titik yang berada dibawah bagan kendali bawah, yaitu pada subgrup ke $12,13,23,24,25,27$. Dengan demikian dapat disimpulkan bahwa rata-rata berat semen pada bagan kendali $\bar{X}$ berada diluar batas kendali.

Dapat dilihat berdasarkan hasil analisis bagan kendali $\bar{X}$ pada Gambar 2, data normal tanpa pencilan memberikan 12 titik yang berada di luar batas kendali sedangkan dengan data normal dengan pencilan menghasilkan11 titik yang berada diluar batas kendali. Maka dapat disimpulkan bahwa bagan kendali shewhart sensitif terhadap pencilan.

Nilai $R$ data berat semen normal tanpa pencilan diplot dengan batas kendali untuk bagan kendali $R$, sehingga dihasilkan bagan kendali pada Gambar 3 .

Dari plot yang diperoleh pada Gambar 3 dapat dilihat bahwa pada bagan kendali $R$ terdapat 1 titik yang berada di luar batas kendali yaitu pada subgrup 


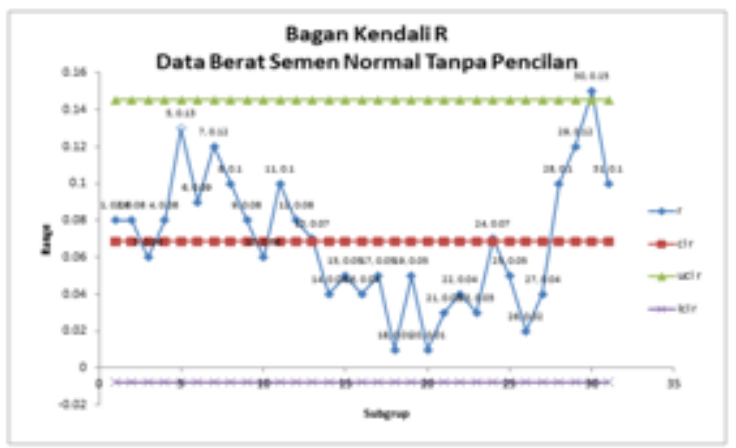

Gambar 3. Bagan Kendali $R$ dengan data normal tanpa pencilan

30 (bulan Juni 2015). Dengan demikian dapat disimpulkan bahwa variasi subgroup berdasarkan rentangan subgrup berada diluar batas kendali.

Pada data berat semen normal dengan pencilan dan dengan menggunakan metode pencarian batas kendali yang sama, sehingga plot yang dihasilkan akan seperti pada Gambar 4.

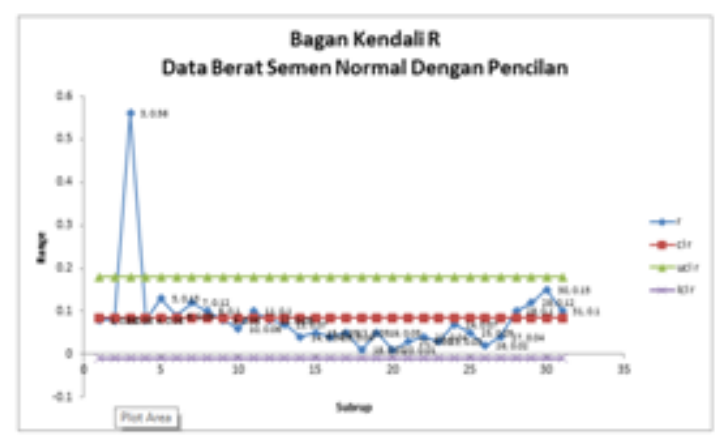

Gambar 4 . bagan kendali $R$ data berat semen normal dengan pencilan

Dari plot yang diperoleh pada Gambar 4 dapat dilihat bahwa pada bagan kendali $R$ terdapat satu titik yang berada di luar batas kendali yaitu pada bulan Maret 2015 . Dengan demikian dapat disimpulkan bahwa variasi subgrup berdasarkan rentangan subgrup berada diluar batas kendali.

Untuk membuat bagan kendali Robust untuk data berat semen normal tanpa pencilan akan dicari penduga HL dan SBL untuk setiap subgrup dengan aturan pada metode, sehingga akan diperoleh bagan kendali pada Gambar 5.

Dari bagan kendali Robust pada Gambar 5, dapat dilihat bahwa tidak ada penduga HL yang berada diluar batas kendali. Selanjutnya bagan kendali Robust dengan data normal tanpa pencilan di atas akan di analisis apakah penduga HL di dalam batas kendali tersebut dalam keadaan terkendali.

Meskipun seluruh data berada di dalam batas kendali, namun bagan kendali 


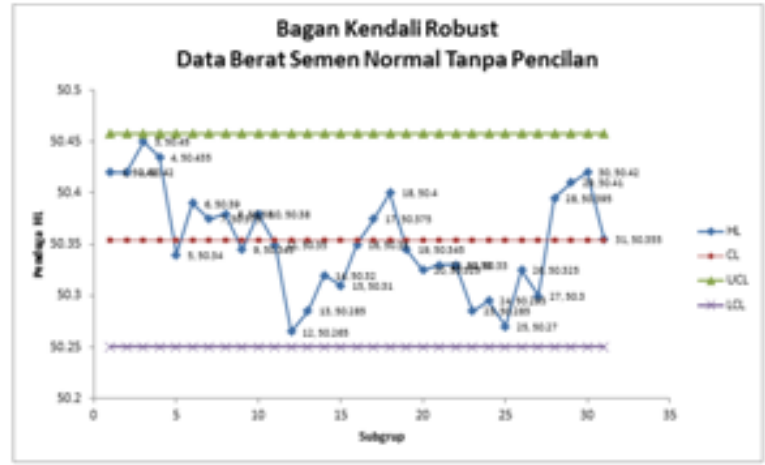

Gambar 5. Bagan kendali Robust data normal tanpa pencilan

Robust tersebut memiliki pola yang tidak acak. Ini terlihat dengan adanya sembilan titik berurutan yang berada di bawah garis pusat, yaitu pada data ke 19 sampai data ke 27.

Nilai penduga HL untuk setiap subgrup di plot kedalam bagan kendali, dengan batas-batas kendali untuk bagan kendali Robust. Sehingga bagan kendali akan terbentuk seperti pada Gambar 6 .

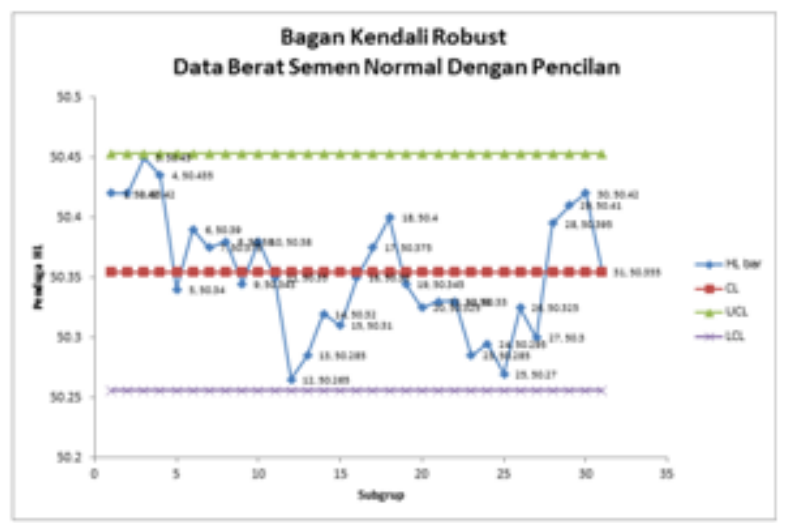

Gambar 6. Bagan Kendali Robust data normal dengan pencilan

Dari bagan kendali Robust pada Gambar 6, dapat dilihat bahwa tidak ada penduga $H L$ yang berada diluar batas kendali. Maka dapat disimpulkan bahwa penduga $H L$ pada sampel berada dalam batas kendali. Walaupun pada data yang sudah dimodifikasi diberikan sebuah data pencilan, tapi tidak membuat bagan kendali Robust diatas tidak berada diluar batas kendali.

Setelah diplot ternyata bagan kendali Robust data berat semen normal dengan pencilan dengan bagan kendali Robust data berat semen normal tanpa pencilan ternyata tidak berbeda. Ini berarti bahwa bagan kendali Robust tidak sensitif ter- 
hadap pencilan. Sehingga semua datanya berada dalam batas kendali. Selanjutnya akan di analisis apakah bagan kendali ini merupakan bagan yang terkendali. Dapat kita lihat pada bagan kendali Robust (data pencilan) ini terdapat sembilan titik berurutan di bawah batas kendali.

\section{Kesimpulan}

Berdasarkan bagan kendali Shewhart dan Robust terhadap data berat semen normal tanpa pencilan dan data berat semen normal dengan pencilan, diperoleh bahwa proses tidak terkendali secara statistik dengan terdapatnya nilai $\bar{X}$ dan $R$ yang berada di luar batas kendali.

Sedangkan dengan bagan kendali Robust untuk data berat semen tanpa pencilan dan data berat semen normal dengan pencilan dapat dilihat bahwa tidak ada penduga $H L$ yang berada di luar batas kendali, namun bila dilakukan analisis bagan kendali dapat dilihat adanya semmbilan titik (penduga $H L$ ) yang secara berurutan berada di bawah garis pusat. Sehingga dapat disimpulkan bahwa proses tidak terkendali secara statistik.

Setelah diplot, bagan kendali Shewhart dan bagan kendali Robust terdapat perbandingan yang cukup jelas. Bagan kendali Robust data berat normal dengan pencilan dengan bagan kendali Robust data normal tanpa pencilan ternyata tidak berbeda, yang berarti bahwa bagan kendali Robust tidak sensitif terhadap pencilan, sehingga semua data berada dalam batas kendali. Sedangkan pada bagan kendali Shewhart terdapat perbedaan antara bagan kendali Shewhart dengan pencilan dengan bagan kendali Shewhart tanpa pencilan. Ini berrarti bagan kendali Shewhart sangat sensitif terhadap data pencilan.

\section{Daftar Pustaka}

[1] Alloway, J. A, Jr. dan Raghavachari, M. 1990. Control Chart Based On The Hodges-Lehmann Estimator. Journal of Quality Technology, 23(4): 336 - 347

[2] Besterfield, D.H. 1998. Quality Control. Pretice-Hall, Inc., New Jersey

[3] Eddy Herjanto. Manajemen Operasi. Edisi Ketiga. Grasindo

[4] Grant, L.E \& R.S. Leavenworth. 1989. Pengendalian Mutu Statistis. Erlangga, Jakarta

[5] Keats, J.B. \& D.C. Montgomery. 1991. Statistical Process Control in Manufacturing. Marcel Dekker, Inc., New York

[6] Montgomery, D, C. 2009. Introduction to Statistical Quality Control. Sixth Edition. Jhon Wiley and Sons, Inc, New York

[7] Quesenberry, Charles P. 1993. The Effect of Sample Size on Estimated Limits for $x$-bar and $x$ Control Chart. Journal of Quality Technology 25 (4): 237 - 247

[8] Siegel, S. 1992. Statistik Non Parametrik untuk Ilmu-ilmu Sosial. PT.Gramedia. Jakarta. 